\title{
Variaciones sobre el autorretrato en la poesía última
}

\author{
Laura SCARANO \\ Universidad Nacional de Mar del Plata/ Conicet, Argentina
}

\begin{abstract}
La poesía es el espacio donde el yo sucede. $\mathrm{Al}$ articularse en términos espaciales instaura un fluir también temporal: es un cronotopo; y por ende lo es su sujeto -sujetado a dicho devenir-. Por encima de las variantes gramaticales que adopte el hablante, en el poema se fragua la subjetividad del poeta, desplazada, diferida, suplementada. El autorretrato exhibe ese proceso de recreación ficcional, atento tanto a la «figura» como a su «fondo», el contexto histórico y las convenciones literarias. Analizamos varios ejemplos de autorretratos poéticos actuales para ver las tensiones entre el efecto de verosimilitud y la búsqueda de dislocación del modelo. $\mathrm{Y}$ en esa trama relacional mostraremos su parentesco con la autopoética como tipo discursivo, para exhibir en primer lugar el perfil artístico del yo, sus motivaciones y proceso creador.
\end{abstract}

Keywords: autorretrato, poesía, autopoética, siglo xxI, España

Yo soy, yo no soy. El anacronismo es no preguntarse cómo, desde dónde.

Erika Martínez

No se equivocaba Neruda cuando afirmaba: «Si me preguntáis en dónde he estado debo decir sucede...», en su poema titulado «No hay olvido (sonata)»', porque la subjetividad hace su nido en el discurso y este se forja en una cadena de letras, semas, frases: deviene palabra. La poesía es el espacio donde el yo sucede. Al articularse en términos espaciales (en la página o pantalla) instaura un fluir también temporal: es una secuencia en ambas dimensiones, un cronotopo; y por ende lo es su sujeto -sujetado a dicho devenir-. Por encima de las variantes gramaticales que adopte el hablante del enunciado, en el poema se fragua la subjetividad del poeta -desplazada, diferida, suplementada-, que oculta como una mamuschka un carozo impenetrable debajo de tantas capas. El lenguaje es la forma que nos ha sido dada para construir su sentido, atisbar ese núcleo, sin agotarlo nunca, sin comprenderlo en su totalidad.

En un artículo reciente, abordé la categoría de «lo menor» para entender las formas en que los jóvenes poetas en España están intentando articular dicha subjetividad ${ }^{2}$. El cuestionado yo no desaparece, pero se vuelve

Pablo Neruda, Residencia en la tierra, Buenos Aires, Losada, 1971, p. 133.

2 Laura Scarano, «Poéticas de lo menor en el hispanismo transatlántico», El taco en la brea, 
fractal, diseminado. El auto-relato adquiere otra textura: es consecuencia del discurrir sobre lo real, sin que el yo detente un lugar de privilegio, pero sin perder tampoco su pulsión introspectiva. Su naturaleza siempre está en construcción, atravesada por la movilidad, la ubicuidad, el descentramiento. Para Luis Bagué y Alberto Santamaría es «una especie de sujeto-ahí»3, que se va desembarazando de solemnidad y gana en evanescencia, como las identidades líquidas de las que nos habla Zygmunt Bauman. Figuras rotas, descalabradas, disponibles, en fuga; vacías pero ávidas, llenas de espacios blancos, entre el punctum y el píxel... ¿quién dice yo en el poema del nuevo siglo? Y mejor, como afirma Erika Martínez en el epígrafe que elegimos: «¿cómo [dice yo], desde dónde?»4.

Para Alberto Santamaría, estamos frente a una modificación radical del estatuto del artista, ya que «la nueva poética pretende que el poeta sea él mismo una cosa que se derrama entre las cosas" ${ }^{5}$. Esto no implica una abolición ya que, como bien argumenta José Andújar Almanza, esa falta de unidad se manifiesta en un doble sentido: «indagaciones biográficas que acaban adquiriendo la forma de una poética... reflexiones semánticas que se confunden con el autorretrato» ${ }^{6}$. Para Miguel Ángel García, los poetas jóvenes «no han roto con la ideología de la palabra poética en tanto que expresiva de la subjetividad», sin embargo no creo que obedezcan todavía a lo que él denomina «la sustanciación de lo poético propia de la ideología burguesa en torno al género» ${ }^{7}$. Parece demasiado aventurado también afirmar que la poesía de hoy «obedece a la era del epílogo o la post-palabra ${ }^{8}$, precisamente porque la matriz autorreferencial no ha remitido. Baste citar la desembozada confesión de Elena Medel (I985) para comprobarlo: «Concibo mi poesía como una forma de espectáculo íntimo, de exhibición para la que necesito una excusa ${ }^{9}$, o como afirma Ana Gorría, con palabras de George Steiner:

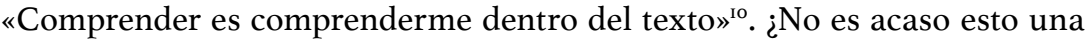

n. 2, 2014. Reeditada en Círculo de Poesía, año 6, 2015. En http://circulodepoesia.com/2015/o9/ poeticas-de-lo-menor-en-el-hispanismo-transatlantico/ [28.2.20I7].

3 Luis Bagué Quílez y Alberto Santamaría (eds.), Malos tiempos para la épica. Última poesía española (2OOI-2OI2), Madrid, Visor, 2013, p. 24.

4 Erika Martínez, «Valores portátiles: el sujeto bajo crítica», en Luis Bagué Quílez y Alberto Santamaría (eds.), op. cit., p. 64.

5 Alberto Santamaría, «Lo alucinado y lo (nuevo) sensible», en Juan Carlos Abril (ed.), Deshabitados, Granada, Diputación, Colección Maillot Amarillo, 2008, p.73.

6 José Andújar Almansa, «Poesía última (Apuntes del natural)», en Juan Carlos Abril (ed.), Gramáticas del fragmento. Estudios de poesía española para el siglo XXI, Granada, Asociación Cultural Cancro, 20II, p.53.

7 Miguel Ángel García, «Gramáticas de la creación en la joven poesía española», en Juan Carlos Abril (ed.), op. cit., p. 95.

8 Miguel Ángel García, op. cit., p. 99.

9 Miguel Ángel García, op. cit., p. Io8.

Io Miguel Ángel García, op. cit., p. II7. 
prueba de fe en el lenguaje, aunque el resultado sea incierto? Quizás lleva razón Ángel Luis Luján Atienza cuando sostiene que «el problema de la identidad es en realidad un problema de la manera de representar ${ }^{\text {II }}$. De ahí que la poesía hoy siga siendo fuertemente metadiscursiva. Por eso, más que hablar del yo, el poeta indaga en «las maneras de hablar del yo» y traslada la problemática del sujeto a su auto-representación ${ }^{12}$.

Después de escribir muchas reflexiones teóricas en torno al sujeto poéti$\mathrm{co}^{13}$, quisiera detenerme acá más cerca de la escritura que de los postulados conceptuales. Josep María Rodríguez nos ofrece para ello una interesante antología titulada Yo es otro. Autorretratos de la nueva poesía (200I $)^{14}$, donde examina esta nueva naturaleza del sujeto. Si bien replica en su título la célebre consigna de Rimbaud, estamos lejos del extrañamiento simbolista o la diseminación vanguardista. Me animaría a proponer una sustitución verbal del tipo: «Yo es/soy/somos otros», porque la pulsión de auto-nominación sigue siendo poderosa, pero las conjugaciones del verbo se solapan, unidas y alternadas, como si pudieran enunciarse en «una cuarta persona del plural»» El presente se vuelve su único asidero, y decir yo es admitir una identidad hojaldrada, que se despliega en una proliferación de rostros distorsionados.

El autorretrato como género «no es solamente un ejercicio de representación mimética, sino también un proceso de recreación ficcional», como nos advierte Teresa González Arce ${ }^{16}$. Margarita Iriarte ha insistido además en la importancia de vincular la «figura» retratada con su «fondo», es decir, el contexto histórico y las convenciones literarias ${ }^{17}$. Aunque es posible encontrar ciertas características que perduran, como el acento en la descripción del exterior (prosopografía) y del interior (etopeya), la coincidencia entre el autor del retrato y persona retratada y la especificación de datos precisos que vinculen a ambos (nombre propio, fechas, lugares, domicilios,

II Ángel Luis Luján Atienza, «El mundo de la nueva poesía española. Algunas notas sobre la referencialidad del discurso poético», en Juan Carlos Abril (ed.), op. cit., p. I34.

I2 Ángel Luis Luján Atienza, op. cit., pp. I37.

I3 Laura Scarano, Los lugares de la voz. Protocolos de la enunciación literaria, Mar del Plata, Melusina, 200o. Y Palabras en el cuerpo: Literatura y experiencia, Buenos Aires, Biblos, 2007.

I4 Josep María Rodríguez (ed.), Yo es otro. Autorretratos de la nueva poesía, Barcelona, DVD, $200 I$.

I5 Distorsiono aquí el uso original que le da Vicente Luis Mora a esta «persona gramatical» tomada de lenguas aborígenes americanas, en su reciente antología: La cuarta persona del plural. Antología de poesía española contemporánea (1978-2015), Madrid, Vaso Roto ediciones, 2016, p. I3. I6 Teresa González Arce (coord.), Triunfar de la vejez y del olvido. Miradas sobre el autorretrato literario en la España contemporánea, México, Arlequín, 2013. En su libro son interesantes los estudios de $\mathrm{M}^{\mathrm{a}}$ Ema Llorente, Jorge Ortega y Luis Vicente Aguinaga, que enfocan el autorretrato lírico en la poesía española actual. Del mismo modo, es un valioso aporte el estudio y antología de José Antonio Mesa Toré, «Los ojos dibujados. El autorretrato en la poesía española y el arte contemporáneo», Litoral, n. 234, 2002, pp. 14-205.

I7 Margarita Iriarte, El retrato literario, Pamplona, Universidad de Navarra, 2004, p. III. 
parentescos coincidentes con los del poeta empírico), el autorretrato actual no persigue un efecto de verosimilitud. Sí en cambio establece una trama relacional con la autopoética como tipo discursivo, ya que en general esta se apoya en un retrato del poeta como tal, indagando en su quehacer artístico, sus motivaciones, su proceso creador.

Podríamos definir el molde del autorretrato lírico actual con una figura retórica llamada palíndromo, como la siguiente: «Soy yos». Leído de ambos lados -de izquierda a derecha y viceversa- enuncia lo mismo, la pluralidad del pronombre, desafiando la concordancia (un singular verbal que se predica como plural). Parece acertada porque sugiere «la multiplicidad, la inversión especular y la paradoja del sujeto posmoderno que se interroga sobre su identidad», en palabras de Manuel Alberca ${ }^{18}$. Lejos del uso lúdico de la imagen, sirve para pensar el carácter polifacético y versátil de las subjetividades que nos constituyen a diario, y que yo he llamado identidades alter(n)adas, signadas por la alteración y la alternancia al mismo tiempo. «¿Quién dice yo?» reemplaza el interrogante esencialista propio de la modernidad: «¿quién soy yo?». Y profundiza otras cuestiones: ¿puede el lenguaje decirme? ¿Cómo nombra la poesía esa proliferación de yos?

Para comenzar a responder estas preguntas me detendré en la mencionada colección de autorretratos de Josep Rodríguez, ya que, como ha señalado Ruiz Casanova, es posible abordar «la antología como libro y no como género ${ }^{19}$, y esta es muestra generosa de las nuevas variantes identitarias. Por su propuesta temática, nos servirá de excelente mapa de ruta para recorrer algunas articulaciones del autorretrato lírico actual. Una de las virtudes del antólogo Josep Rodríguez ha sido ampliar la nómina para incluir «poetas no únicamente en castellano sino también en asturiano, catalán, euskera y vasco $»^{20}$. Partiendo del variopinto abanico de voces escogidas, Rodríguez nos advierte sin embargo que «esta no es otra antología de poesía joven», sino de poetas nacidos entre 1965 y I977, que evidencian una «voluntad de cambio» y una "actitud de búsqueda», para «ampliar el realismo dotándolo de misterio» ${ }^{21}$. En qué consiste el realismo y hacia qué nuevas fronteras se encamina amerita una reflexión más profunda que lo que estas páginas permiten. Quedémonos aquí con la acertada selección de poemas, que nos

I8 Manuel Alberca toma la expresión del título de una novela del narrador español Pablo David Pérez Rodrigo, que ganó el premio «La ventana de Millás» en España en 2003 (registrado en Babelia-El País, 25 de enero de 2003, p. 9), y lo cita en su libro: El pacto ambiguo. De la novela autobiográfica a la autoficción, Madrid, Biblioteca Nueva, 2007, p.I9.

I9 José Francisco Ruiz Casanova, «Canon e incorrección política: poética de la antología», en Andrés Sánchez Robayna y Jordi Doce (eds.), Poesía hispánica contemporánea. Ensayos y poemas, Barcelona, Galaxia Gutenberg/ Círculo de lectores, 2005, p. 217.

20 Josep María Rodríguez (ed.), op. cit., p. II.

2I Josep María Rodríguez (ed.), op. cit., pp. I2-I4. 
llevarán a ampliar el concierto a otras voces, que también sucumben al seductor ejercicio de autorretratarse.

Bajo la advocación de los conocidos versos de Antonio Machado («Mi soliloquio es plática / con este buen amigo»), Antonio Lucas (I975) inicia su texto con la rotunda negación de su identidad verbal, a pesar del acto en sí que lo pronuncia: «Yo no soy el que digo, / aquel que viene y luego / da un grito enterrado...»" . El desdoblamiento del yo en un «aquel que nunca más he visto» confirma el emblema por antonomasia del autorretrato aludido en el título, «Ahora que te ven desde el espejo». El «buen amigo machadiano», el «yo es otro» de ese soliloquio, donde «la heterogeneidad del ser» no anulaba el diálogo entre ambos rostros, reaparece en este texto, pero enfrentados especularmente, ahondando la distancia y una irremediable separación: «Ya sabes. Que nunca va contigo / aquel que te acompaña» ${ }^{23}$. Interesante es el cotejo con sus reflexiones teóricas, donde no duda en afirmar la voluntad constructiva de la literatura: «Hay una forma de estar en el mundo a través del poema. No como modo de operar en la vida, sino como forma de hacerla comprensible, de mejorarla», ya que el lenguaje es «la llave que permite asimilar mejor lo que se vive» ${ }^{24}$.

Andrés Neuman (I977) se dibuja en su «(Autorretrato al óleo)», consignando su título entre paréntesis, con la sutil relatividad que lo caracteriza. El yo es una paleta de contrastes: «Una mancha de azul, otra de rojo. / Un gesto de caricia, uno de rabia. / Una zona de luz y el resto en la penumbra». Escorzo, perspectiva, profundidad, en un ejercicio verbal donde «se mira de lejos» o «una mano, curiosa, / roza el centro». Apenas un deíctico pronominal («cierto gozo en hundirme») delatan a este yo que se ausenta del óleo. Lo que queda es apenas «una pose volcada y algo hermética, / una impresión de concha $»^{25}$. En suma, un yo inasible, reacio a la pintura de sí mismo.

Ana Merino (I97I) se atreve al auto-relato en «Breve biografía de angustias infantiles» y convierte su texto en una cosmogonía, donde los protagonistas de la niñez se adueñan de su cuerpo: «Soldados sobre mis párpados dormidos», «los sueños tejen sobre la piel sensaciones imposibles». Una prosopopeya que recorre su historia «desde el regazo de mi madre», que la protege contra las pesadillas, «el fin del mundo» y la muerte como «un gran hongo cubierto de humo blanco». El yo es esa memoria de la angustia en la frente, que «sueña imágenes reales» y le roba a «los niños el corazón del tiempo». No es una angustia de juguete: «es mi niñez que camina sonámbu-

22 Antonio Lucas en Josep María Rodríguez (ed.), op. cit., p. 27.

23 Antonio Lucas, op. cit., p. 28.

24 Antonio Lucas, «La realidad de lo visible (aproximación y sospechas sobre una construcción de la mirada)», en Luis Bagué Quílez y Alberto Santamaría (eds.), op. cit., p. 76.

25 Andrés Neuman en Josep María Rodríguez (ed.), op. cit., p. 3 I 
la por la casa/ y grita sudorosa que ha visto el fin del mundo ${ }^{26}$. Su autorretrato es un trozo de biografía fantasmagórica, apenas una metonimia de la niña que fue, desplazada en la mujer que la recuerda y actualiza.

Luis Muñoz (1966) adelgaza su retrato en una estampa con lugar y fecha: «Café Hafa, Tánger, febrero 200I». Un personaje sentado en la terraza ausculta el fragmento de mundo que se recuesta frente a sus sentidos: «Ha clavado los ojos en un punto del fondo", «puede escuchar cada cosa que ha visto», «el cigarrillo humea en dirección al sur». De la fotografía surge evanescente la tensión simbólica que se resuelve en meditación existencial: «le hace saber que vive en las bisagras del tiempo, / solo un modo de andar esquivando sus hojas». ¿Hay aquí un autorretrato?, se preguntará el lector. Si escribir es una forma de articular un yo (aunque sea su ausencia), el final del poema nos remite a ese laborioso ejercicio verbal de suturar la identidad: «La poesía, entretanto, / recorta el té del vaso y las colinas» ${ }^{27}$. El poeta niega su autorretrato y se oculta en el ojo de la cámara que atisba la otredad. Otra forma de decir «Yo es otro».

En «La huella», Lorenzo Oliván (1968) registra los restos del yo reducidos a manchas de tinta, que intentan transcribir «la detallada historia de quién eres». La distancia que impone la interlocución a un tú juega con el desdoblamiento del sujeto. Pero la historia nos supera, viene de lejos y va más allá de la minúscula partícula que somos: «Tu historia» «la cifró en tu carne un tiempo ignoto / muy superior al tiempo en el que vives». Eso somos y eso eres, parece afirmar: una historia «borrosa y transparente, / sencilla y, a la vez, indescifrable». Y concluye el poema con la risa cósmica de un absoluto que se nos escapa: «Un dios burlón en ti lee entre líneas» ${ }^{28}$.

Javier Rodríguez Marcos (1970) experimenta en «Otro» el extrañamiento que nos devuelve el espejo. Más que desconocimiento, se obstina en su negación: «Más allá, en el espejo, / no soy yo, / esa sangre no es mía». El yo es apenas una lexía; no denota una realidad: «Yo me he quedado aquí sin otra cosa / que la palabra yo». Y la ajenidad introduce una deriva, donde el cuerpo invadido es «una casa con los cristales rotos / que amenaza ruina», y en ella «se esconde un animal / que espía mis movimientos». El lugar del yo es usurpado por «Alguien, Cualquiera. Otro». Una vez desatada la persecución («me persigue y se viste con mi ropa, / piensa mis pensamiento») no hay escape posible; la pérdida es inminente; la posesión irremediable. Solo queda una salida («la única ventaja»), cerrar los ojos para desvanecer la imagen del espejo: «la batalla, los muertos, los heridos, / cierro los ojos / y desaparece ${ }^{29}$.

26 Ana Merino en Josep María Rodríguez (ed.), op. cit., p. 39.

27 Luis Muñoz en Josep María Rodríguez (ed.), op. cit., p. 40.

28 Lorenzo Oliván en Josep María Rodríguez (ed.), op. cit., p. 50.

29 Javier Rodríguez Marcos en Josep María Rodríguez (ed.), op. cit., pp. 54-55. 
El poeta asturiano Xuan Bello (1965) titula «Poema inacabáu» a un remedo discursivo donde emula una declaración de fe, invirtiendo sus protoco$\operatorname{los}^{30}$ : «Yo, que ya no creo en lo que escribo», «yo, a los veintimuchos años de mi vida, en Oviedo, declaro...». Y precisamente el contenido de su enunciado contraría las expectativas del tipo discursivo que parodia, ya que afirma «la vida que huye de mis manos», el «frío de la noche», «la luz en una ventana de quien no me espera». Da paso luego a una serie de predicados que expresan su naturaleza desconcertada: «Yo tengo por destino lo incierto / y por pasado la nostalgia». El yo sufre un extrañamiento ontológico que no le impide reconocerse en su nombre propio: «Yo, Xuan Bello...». Se identifica en sus lecturas, en sus pérdidas y en sus ganancias, en el amor y el desamor, como las inevitables dobles caras de la moneda: «yo fui feliz y fui infeliz, me amaron y amé». El saldo es un poema que siempre está inacabado, como reza su título, porque escribe una vida que aún está sucediendo: «La tarde ha traído la soledad, versos viejos releídos / con pasión ya fingida». Y como Pessoa, para Bello el poeta es «un fingidor»: «Enmohecidos versos viejos / que repito aquí / fingiendo pasión, fingiendo amor, fingiendo ser / estas palabras que digo» ${ }^{31}$.

En «Retrato», Álvaro García (1965) nos devuelve al rítmico ondular de una meditación que de inmediato nos sumerge en la etopeya del yo, en su armonía con el cosmos: «Aspiro al absoluto de estar vivo / y le hago sitio al aire de este mundo». Esta «plenitud» que celebra al retratarse habla más de una armonía anhelada que vivida. Como aquel acorde de «el mundo está bien hecho» de Jorge Guillén, el hablante da nombre al «vino leve del vivir» y cuida «las horas sin gloria de la gracia». Todas sus acciones confirman una subjetividad a contramano del lamento o la queja; por el contrario exalta la "plenitud»: «Invoco aquí el sosiego, el entusiasmo», «Presencio el azul tenue de un mundo matinal, sereno y frío». El poema es un acto de fe que se modula en plural: «Nos queda el sol. Que roza nuestra piel / y que resiste cuando no resistes. // Y los colores hechos compañía, / y la amistad que suena como un río». Aquella aspiración «al absoluto de estar vivos» con que comenzó el texto parece tener feliz concreción en esta pintura celebratoria, aunque surge la duda en el lector frente al último verso: «Ahora es posible estar del todo en el retrato $»^{32}$. ¿Será posible transponer el marco y convertir ese rostro acabado en materia real? ¿Creer que en la palabra yo está mi yo, y en la palabra plenitud el trasiego de la existencia cotidiana?

Para Juan Carlos Abril (1974) en su «Segundo autorretrato», escribir-se es concertar una historia de a dos. El yo invoca al tú y evoca una escena en el pasado: «Veíamos fogatas a lo lejos: / la orilla de la playa ardía en fiesta»,

30 Utilizamos la traducción que ofrece el propio autor.

3I Xuan Bello en Josep María Rodríguez (ed.), op. cit., pp. 62-63.

32 Álvaro García en Josep María Rodríguez (ed.), op. cit., p. 64. 
«Era / el silencio que, breve, nos gustaba», «Felicidad, llanura líquida... / el mar, y tú saliendo...» Pero esas intermitentes memorias son atravesadas por un presente verbal que deja atrás los «laberintos, / clavos y tiempo»: «Ahora / esa luz pobre de ventana, / mi fantasía sola» ${ }^{33}$. La dialéctica de soledad y compañía se desenvuelve en una serie vertiginosa de metáforas donde el sujeto recorre el camino hacia el origen de la especie, en su atávica condición de animal solo: «Y yo. / Yo soy un renacuajo -una espiral», o acaso «una matriz / sin gloria», que lucha por volver a reencontrar aquella unidad perdida y «lucha por tus ojos / amarillos y verdes». Ya había escrito un primer «Autorretrato» en El laberinto azul, para examinar su identidad en esas «lentas horas / de desesperación cuando amanece» ${ }^{34}$. Con la alegoría de la torre y el laberinto, o «los animales perseguidos / en banda por viriles cazadores», la introspección agudiza la experiencia del límite («escucho desde dentro la amenaza / de la muerte, segando sin fatiga»), hasta rematar en el inquietante dístico final: «No sabe el prisionero de esta torre / quién se acerca a buscarlo».

Josep M. Rodríguez (I976) adopta un tono magisterial para retratarse en «Última lección», acorde con su regreso al ser del pasado: «en la espiral del tiempo soy un niño / que juega a hacer burbujas de jabón». Pero la memoria no lo salva del sentimiento de vacuidad: «los agujeros negros de la edad, / todo lo que no fue / y lo que ha sido». Es la «última lección» que aprende el sujeto: «es solo una palabra: / abandono». Como para Borges, felicidad y odio son territorios linderos: «Si la vida consiste en ser feliz, / yo aprendo a sentir odio / hacia mí mismo» ${ }^{35}$. Agudamente lúcido sobre la naturaleza hojaldrada de ese yo, Rodríguez profundiza esta matriz en su poemario Arquitectura yo, donde afirma: «...escribo yo.// Y sin embargo a ratos me construyo. / Y sin embargo a ratos me derribo. / O incluso las dos cosas» ${ }^{36}$. En su poética «Memorias de un lector» ratifica esta pulsión de objetivación del sujeto en el lenguaje: «La poesía que me interesa habla de mí» ${ }^{37}$.

Carlos Pardo (I975) en «Un dos piezas» se aventura en un metapoema que confirma la voluntad de la poesía actual por dirimir su estatuto, confirmando su identificación con el sujeto que la escribe: «Al final del poema estaré yo». Es la meta del poeta que indaga sobre sí: «Autorretrato: / la excusa por la voz venida a menos». Un género destinado a la elegía o al réquiem: «Biografía: pretexto / para los funerales del destino. / Una suma de fugas» ${ }^{3}$. Intere-

33 Juan Carlos Abril en Josep María Rodríguez (ed.), op. cit., pp. 69-7I.

34 Juan Carlos Abril, El laberinto azul, Madrid, Rialp, 200I, pp. 58-59.

35 Josep María Rodríguez (ed.), op. cit., p. 77.

36 Josep María Rodríguez, Arquitectura yo, Madrid, Visor, 2012, p. 36.

37 Josep María Rodríguez, «Memorias de un lector», en Juan Carlos Abril (ed.), op. cit., 2008, p. 197 .

38 Carlos Pardo en Josep María Rodríguez (ed.), op. cit., pp. 8o-8I. 
sante es contrastar esta imagen con sus reflexiones teóricas. Por ejemplo en «Notas sobre poesía y caducidad» admite que «el proyecto posmoderno de disolución del sujeto parece especialmente acorde con el moderno mundo del mercado», donde las identidades son asumidas como «bienes de consumo» y persiste una atmósfera social «hostil al individuo», que le adjudica «responsabilidad personal por cada error de la maquinaria» ${ }^{39}$.

Inevitable también la mención al conocido poema de John Ashbery (I927) «Self-portrait in a convex mirror» (I975), que retomará Fruela Fernández (1982) en su "Autorretrato en un espejo convexo», confirmando la paternidad del poeta norteamericano sobre muchos de los jóvenes españoles. El emblema del espejo y sus distorsiones, el des- y re-conocimiento como vías alternas y dispares para mirar el propio yo, el protagonismo del otro como alteridad (heterogeneidad del sí mismo y vinculación con la otredad real) se conjugan en este texto del poeta asturiano que bien puede servirnos para cerrar este recorrido por la antología de Rodríguez. Su íncipit es un réquiem; la muerte desdobla al yo en el otro: «Hace tiempo que he muerto, / pero ahora / regreso [...] sabiendo que soy otro». La conjugación verbo-pronombre establece una contra-gramática rimbaudeana: «Porque yo es otro, / porque tú es otro». Reflejos deformados del original, memorias fraudulentas; el cierre elegíaco confirma la extrañeza de esta subjetividad siempre en fuga: «El tiempo se ha llevado cuanto fuimos // y ahora eres las sombras que te habitan $»^{40}$.

Como vemos, todos estos poetas parecen decirnos que el sujeto es tan incognoscible como el resto del mundo. El progresivo extrañamiento ahonda ribetes de vacío ante la propia definición del yo, que sin embargo intenta recuperar valores frente a un imaginario social signado por la anomia, la falta de vínculos, la incertidumbre radical, como la que plantean en su antología transatlántica (Poesía ante la incertidumbre [20II ${ }^{4 I}$ ) varios poetas españoles y latinoamericanos. La experiencia de ajenidad enfrenta al yo con el enemigo, el acosador, en Los ojos del pelícano (2012) de Fernando Valverde (I980): «Dentro de este poema pasa un lobo». El peligro del afuera, animalizado en el paso sigiloso de ese lobo que «recorre una ciudad / que miró confiada hacia el futuro», se trueca en enemigo íntimo: «en este poema espera un lobo / que ha venido a buscarme». El otro es también yo, y yo soy ese extraño que me acosa: «Aunque intente estar quieto y no hacer ruido / salta por las palabras

39 Carlos Pardo, «Notas sobre poesía y caducidad», en Juan Carlos Abril (ed.), op. cit., 2008, pp. I3I-I40, citado pp. I39-I40.

40 Fruela Fernández en Ariadna G. García, Guillermo López Gallego y Álvaro Tato (coords.), Veinticinco poetas españoles jóvenes. Antología, Madrid, Hiperión, 2003, pp. 432-433.

4I VV.AA., Poesía ante la incertidumbre, Antología (Nuevos poetas en español), Madrid, Visor, 2011. 
un recuerdo / que me arranca un aullido y me devora $»^{42}$. Del mismo modo, en «El bosque», este se vuelve metáfora del peligro: «Hay tanta incertidumbre allí en el bosque». Es la espesura, lo desconocido, ante el cual la voz, «tan rota y tan cobarde», no logra sobreponerse. Pero es también un fatal sucedáneo del yo: «es mejor estar quieto [...] / aunque el bosque sea yo y alguien huya de mí»43. Dos autorretratos elusivos, que distancian mediante correlatos (un lobo, el bosque) la disyuntiva del sujeto ante su propia extranjería.

Raquel Lanseros (I973) abre su último poemario, titulado Las pequeñas espinas son pequeñas (2013), con una admisión existencial: «Mil veces he deseado averiguar quién soy», pero admite con serena sabiduría que «no está en mí la verdad», «la verdad no está en nadie». La subjetividad se forma en las palabras compartidas, por eso propone una ética plural, desde el título «Contigo» y lo vuelve un conjuro. El lenguaje es un acto de fe, el «último don» que pide para el final: «Poned en mi sepulcro las palabras», «La verdad no está en nadie, pero acaso/ las palabras pudieran engendrarla»44. No casualmente termina este libro con un «Himno a la claridad», donde la introspección no anula la mirada sobre la realidad y los otros, sobre «la tierra / que es nuestro hogar común, / el verdadero». Para ello, admite unas pocas certezas irrebatibles: «Sé que tengo sentido porque vivo», «ante el placer de respirar me postro. // No hay verdad más profunda que la vida» ${ }^{45}$. Aunque no lo parezca, es un (auto)retrato que postula el autos en términos de comunidad.

Este camino incierto, este proceso de desvelamiento con retrocesos, fracasos y desconcierto, no implica abjurar de todo posible acercamiento a los hombres y al mundo concreto. Ya lo manifiesta Rafael Espejo (1975) en ese magnífico poema titulado «Idéntico a lo mismo»: «También yo soy planeta. / Valgo igual que una mosca», "Solo un envase soy», «Y no soy yo quien habla / sino la voz del mundo» ${ }^{46}$. Estos poemas intentan ser variaciones sobre un autorretrato que ha perdido su empaque clásico, que no tiene marcos definidos, pero que sigue empeñado en dar forma por el lenguaje a la «insoportable levedad» de aquel que dice yo.

Con una convicción que compartimos, Erika Martínez manifiesta que «la ética de la poesía actual se articula como crítica» y es a su vez «un ejercicio de responsabilidad», porque aspira a «ofrecer una comprensión del mundo y del yo que no evite sus conflictos» ${ }^{47}$. Poner bajo la lupa nuestra subjetividad y dejar que el lenguaje nos construya no significa claudicar ni

42 Fernando Valverde, Los ojos del pelícano, Colombia, Icono, 2012, p. 63.

43 Fernando Valverde, op. cit., p. 46.

44 Raquel Lanseros, Esta momentánea eternidad. Poesía reunida (2005-2016), Madrid, Visor, 20I6, p. I78.

45 Raquel Lanseros, op. cit., pp. 239-240.

46 Rafael Espejo, Nos han dejado solos, Valencia, Pre-Textos, 2009, pp. 30-3I.

47 Erika Martínez, op. cit., pp. 5I, 54. 
abolir el sentido. Por el contrario, la poesía que aquí recorrimos demuestra que el arte sigue siendo una eficaz herramienta para pensarnos, en los entresijos de un imaginario global que nos atraviesa sin pedirnos permiso, y de un inconsciente ideológico que nos constituye, aunque ignoremos todas sus implicancias. 